\title{
Ángelus y otros falsos demonios: desescrituras sacras en la poesía de Blanca Varela
}

\author{
Beatriz Velayos Amo \\ Universidad Autónoma de Madrid
}

Resumen: En este trabajo se analizará el proceso de reescritura y desmitificación al que Blanca Varela somete el texto bíblico. A través de la profanización de diversas figuras del canon católico y especialmente del diálogo truncado con un Dios ausente, Varela termina reconfigurando en su poesía su visión de la creación y llegando a la conclusión de que, ante un Creador que no responde, la propia voz poética debe convertirse en la creadora de la realidad del poema.

Palabras clave: Blanca Varela, poesía peruana, catolicismo, reescritura.

\section{Angelus and other false demons: sacred counterwriting in Blanca Varela's poetry}

Abstract: In this work, I intend to analyze how Blanca Varela submits the biblical text to a process of rewriting and demystifying. Through profanizing several figures from the Catholic canon and specially through a broken dialogue with an absent God, Varela ends up reconfiguring in her poetry her vision of Creation and coming to the conclusion that, before a Creator that doesn't respond, the poetic subject herself must become the creator of reality within the poem.

Keywords: Blanca Varela, peruvian poetry, Catholicism, rewriting. 


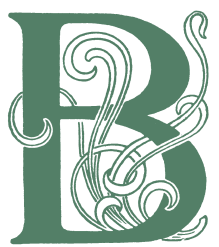

lanca Varela nació en Lima el 10 de agosto de 1926. Se la ha vinculado con artistas como Sebastián Salazar Bondy, Javier Sologuren, Jorge Eduardo Eielson y Fernando de Szyszlo (con quien se casó en 1949), como parte de la generación del 50 peruana. Aunque se ha intentado adscribirla a corrientes como el surrealismo o la poesía pura, es difícil definir con exactitud un estilo unitario a lo largo de su producción, que consta de ocho libros: Ese puerto existe (1959), Luz de día (1963), Valses y otras falsas confesiones (1972), Canto villano (1978), Ejercicios materiales (1993), El libro de barro (1993), Concierto animal (1999) y Falso teclado (2000).

Ina Salazar establece en su estudio sobre la obra de Varela y Eielson que la poesía tiene dos opciones: ritualizar la experiencia y la vida, o profanarla y profanizarla ${ }^{1}$ con la dificultad añadida de que la poesía contemporánea debe definirse por y contra el cristianismo. Varela, que establece en su poesía un diálogo difícil, truncado, con la divinidad, opta claramente por esta segunda opción: la de desacralizar, dudar, transgredir y traspasar las fronteras de lo milagroso para hablar de una experiencia profana. Ya en los propios títulos de sus libros encontramos este afán desacralizador: los valses, música tradicional peruana, se convierten en una más de las falsas confesiones, falsas porque en una confesión siempre se oculta la verdadera naturaleza; el canto que alababa a Dios se hace villano, se hace indigno y pierde toda fiabilidad; los ejercicios materiales hacen clara referencia a los ejercicios espirituales de san Ignacio de Loyola, despojados de su intención original de ser guía en la oración para convertirse en una provocación, en la inversión de valores y en la expresión, ya no de ejercicios materiales, sino maternales, tema omnipresente en la poesía de Varela (Salazar, 2011).

Más allá de estos títulos, la presencia de elementos religiosos a los que Varela aporta su propio significado, vinculándolo con su experiencia corporal y vital, es constante en su obra. Desde el simple juego de palabras hasta la desacralización de figuras y rituales religiosos, la poeta hace referencias constantes a la religión que cumplen el objetivo, en primer lugar, de desacralizarlas.

\footnotetext{
1 Salazar distingue entre ambos términos, pues mientras profanar significa tratar algo sagrado sin el debido respeto, llegando a la blasfemia, profanizar es el hecho de convertir lo sagrado en profano, lo cual no tiene necesariamente un carácter herético ni religioso, sino que también abarca fenómenos como la incorporación de elementos religiosos al imaginario cultural, la denuncia política a través de dichos elementos o incluso la sacralización de elementos profanos como el erotismo.
} 
Varela se apropia, por una parte, de la palabra, entendiendo esta como el Verbo genésico. En la Biblia, la palabra es la forma de creación que elige Dios, pero también existe una identificación ontológica explícita entre la divinidad y la palabra: «En el principio existía el Verbo, y el Verbo estaba con Dios, y el Verbo era Dios» ${ }^{2}$ (Jn 1, 1). En El libro de barro, Varela dice «El verbo anida excéntrico. Jamás en él. Pues todo centro es un camino errado y eso es el verbo, ojo del centro abolido. Silencio» («En una mano la locura, la tempestad», 305) ${ }^{3}$. Por tanto, a la luz de esta relación, es posible ver en estos versos que, para Varela, Dios ya no habita en su templo, en las instancias legitimadas, en el centro de la cultura y de la existencia del hombre, sino que está en los límites, con aquellos desplazados por el sistema. El verbo ya no está en "él", sino en ellos, y por ellos aboga: «ah famélicos glotones vencedores de sirenas. / [...] antes que ustedes otros, cruz en ristre, lágrimas negras como clavos. temor de dios y de hambre» (Ejercicios materiales, «Crónica», p. 288).

Aunque en Ese puerto existe aparece Dios escrito con mayúscula, este término se utilizará con minúscula en el resto de sus poemarios: la ortografía en este caso refleja la relación conflictiva que la poeta establecerá con Dios, de la que ella misma es muy consciente: «Yo creo que siempre he tenido una conversación dudosa con Dios. Para mí, Dios se ha escrito siempre con minúscula. Yo nunca he sido creyente» (Entrevista con Patrick Rosas, 2). En Varela es posible encontrar lo que Cármona-Huechante define como la poética del descenso, «un registro marcado por el radical declive del poder simbólico del lenguaje y que, por ende, testimonia la finitud e inmersión histórica del mismo» (2005: 2). Es decir, el lenguaje en los poemas de esta autora se va desprendiendo de mayúsculas, signos ortográficos y de puntuación y se va desnudando como una manera de simplificarse pero también de centrarse en la expresión, sin dejar que las normas interfieran con su intención última. Retomando la relación del Dios cristiano con la palabra, esta desconfianza en la retórica impropia incluso de su época y su contexto histórico-literario (Cárcamo-Huechante, 2005) pueden interpretarse como la primera de las desacralizaciones que Varela realiza de la figura divina: el despojarla de su mayúscula, su tratamiento privilegiado, pero también de su importancia ontológica.

\footnotetext{
2 La cursiva es propia.

3 Todos los poemas están tomados de Varela, B. Aunque cueste la noche. Ediciones Universidad de Salamanca, Salamanca: 2007, y se indicará tan solo el título del libro, el poema y la página, dentro de esta edición, de donde se citen los versos.
} 
Por otra parte, se describe a Cristo con rasgos palestinos, no por exactitud geográfica, sino como reivindicación de este Dios que habita en los límites: «su barba redonda negra sedosa / su rostro de fakir» (Canto villano, «Cruci-ficción», p. 243), «La sangre del cordero africano es indeleble» (El libro de barro, «La sangre del cordero africano...», p. 295). Cristo es llamado cordero por primera vez por Juan el Bautista: «El siguiente día vio Juan a Jesús que venía a él, y dijo: "He aquí el Cordero de Dios, que quita el pecado del mundo"» ( $n$ 1, 29). En la tradición cristiana, Cristo es el cordero que se ofrece por toda la humanidad, eliminando desde este momento la necesidad de otros sacrificios rituales, que ya no se realizan en las celebraciones cristianas; así lo describe René Girard al analizar el fenómeno del sacrificio: «En Cristo es Dios quien se hace víctima [...] Ya no es el hombre quien hace sacrificios a Dios, sino Dios quien se "sacrifica" por el hombre, entregando a la muerte por él a su hijo unigénito» (2012: 10). Sin embargo, como se verá más adelante, el sacrificio tiene un sentido negativo para Varela, pues la luz - la divinidad - devora lo ofrecido sin dar una garantía de salvación: esta referencia al cordero es otra muestra de su descreimiento, de su conciencia del abandono por parte de Dios.

Al hilo de la identificación trinitaria de Dios y Cristo, este último aparece también tanto compadecido, por ser hijo de un padre ausente, como vilipendiado en la poesía de Varela. Se le describe en Luz de día como un niño crecido que «oraba de una manera extraña, uniendo las plantas de los pies como un simio» («Madonna», 173); y se retoma su figura esperpéntica y la descripción animalística en Canto villano: «de la nada salen sus brazos / su cabeza/ sus manos abiertas / sus palmípedas manos» («Cruci-ficción», p. 243). Como personaje ficticio, Cristo es comparado con otras divinidades de religiones diferentes; la poeta, puesto que no reconoce un único Dios verdadero, se refiere también a «un dios olvidadizo / lo deja sin corazón / sin hígado/ sin piernas para huir»: al igual que este dios se olvida de la Creación, se olvida también de su Hijo y lo deja en la estacada, sin hígado, en una clara referencia al mito de Prometeo (Grimal, 1951).

\footnotetext{
4 Es posible equiparar a Dios con Cristo, no solo en la tradición cristiana a través del dogma de la Santísima Trinidad, sino en el texto bíblico que referencia Varela en sus poemas. Si el Evangelio de Juan comienza diciendo «Y Dios era el Verbo» (Jn 1:1), después afirma: «Y el Verbo se hizo carne, y habitó entre nosotros, y vimos su gloria, gloria como del unigénito del Padre, lleno de gracia y de verdad.» (Jn 1:14). Por tanto, Dios y Cristo son el Verbo, la fuerza creadora, y puede aplicarse el mismo tratamiento a ambos -aunque, como se comentará más adelante, en cierto momento Varela diferencia la figura del Padre ausente y del Hijo abandonado-.
} 
De esta forma, Varela no solo rompe la unión trinitaria entre el creador y su Hijo, sino que lo convierte primero en hombre que comparte con el resto de la humanidad rasgos de raza, género y expresiones de dolor, y después lo incorpora al bestiario que caracteriza su poesía ${ }^{5}$. En estos poemas se animaliza a Cristo, se degrada su carácter sagrado y se le separa de su naturaleza divina equiparándolo al resto de hombres, ya que «el ser humano es rebajado en la poesía de Varela a su condición animal que es la más extrema» (Barrientos, 2008: 225).

En el poema «Vals del Ángelus», Varela ataca frontalmente a la divinidad, dotándola de una corporalidad abyecta y degradada, incorporándola a su bestiario particular como hizo con su Hijo, y lo hace además desde la voz de María, es decir, de quien se dice la esclava del Señor, su servidora más fiel: Varela hace propia la experiencia de las mujeres a las que se les prometió el Paraíso y solo encontraron dolor, abandono y un cuerpo dolorido por menstruaciones, partos y muerte. Al igual que Eielson, Varela recurre a la corporeización y la reescritura de textos religiosos para articular una nueva forma de lo sagrado:

Ambos, y esto es quizá lo más interesante, proponen una reescritura subvertida de textos místicos, en la cual el cuerpo se vuelve central, irguiéndose contra la visión, que desde Platón predomina en Occidente, de "un alma inmortal que el hombre debe aislar, purificar, para separarla de un cuerpo cuya función es sólo la de un receptáculo o tumba" (Salazar, 2011: 2)

Por ello es fundamental que Varela también se dirija a Eva, como representante del primer pecado corporal del ser humano, diciendo «animal de sal / si vuelves la cabeza / en tu cuerpo / te convertirás / y tendrás nombre / y la palabra / reptando / será tu huella» (Canto villano, «Va Eva», 247). Al igual que se equiparaba a Cristo con Prometeo, en este texto no solo hay referencias cruzadas dentro del propio texto bíblico - el animal de sal refiere a la esposa de Lot «que iba tras él, miró hacia atrás y se convirtió en una columna de sal.» (Gén 19, 26) - , sino que, al dejar innominada a la mujer, se nombra indirectamente todas las metamorfosis que sufren las mujeres como castigo o a consecuencia del hombre.

5 Para un estudio en profundidad del bestiario y la construcción de la metáfora animal en Varela, ver "La metáfora animal: en torno al bestiario de Blanca Varela" (Rodríguez Gutiérrez, 2008). 
La voz poética asume esta condición de rebeldía, de hija expulsada de Eva, cuando escribe «esta ínfima y rebelde herida de tiempo que soy / polvo rebelde sí / [...] palabra escrita palabra borrada / palabra desterrada / voz arrojada del paraíso» (Ejercicios materiales, «Malevitch en su ventana», 267). Su condición de poeta, de palabra, se conjuga aquí con la de mujer, que la vincula a todas las desterradas, a todas las voces que han sido arrojadas del paraíso, es decir, de la posición de legitimidad: la palabra borrada es la palabra de todas las mujeres que no pudieron escribir su propia historia. Varela subvierte la idea de castigo que hay en la expulsión, pues el Paraíso supone el verdadero infierno: «regresar al punto de partida / al paraíso irrespirable / a la ardorosa helada inmovilidad» (Ejercicios materiales, «Ejercicios materiales», 278).

No solo Eva, por supuesto, es una mujer relevante en la Biblia; la más significativa para el cristianismo, sin duda, es María, y así lo refleja Varela, al convertirla en verdugo de sus hijos, de quienes han olvidado la dolorosa realidad del mundo para honrar estatuas en los museos: «"a palos los mataré niños míos." advierte, delira, musita, mientras sacude soleada melena y albiceleste gualdrapa. / con leve mano descubre el seno por donde mana sólida vía láctea, llenando la noche del tiempo con dolorida luz redentora.» (Ejercicios materiales, «Crónica», 287). Si tradicionalmente Eva representa la mujer que cae en la tentación, María llega a redimir esta caída como madre virginal, entregada y pura; al presentarla como una madre dolorida, una madre con senos, que sufre y que puede ser capaz de violencia, Varela subvierte esta imagen de "mujer sin cuerpo" y le devuelve la maternidad, la corporalidad, la realidad.

El «Vals del Ángelus», incluido en Valses y otras falsas confesiones, constituye una escena de la Anunciación corrompida con la virgen como centro temático y del discurso, ya que realiza una imprecación contra Dios mismo, que dispone de la joven María tras su entrega: «Entonces María dijo: He aquí la sierva del Señor; hágase conmigo conforme a tu palabra. (Lc 1, 38). En el poema de Varela, ella se entrega a la voluntad del Señor, y se ve convertida en una santa pobre, en figura de museo relegada al lugar más infecto, junto a las letrinas, junto a la suciedad y la inmundicia: «Ve lo que has hecho de mí, la santa más pobre del museo, la de la última sala, junto a las letrinas» (201). María se muestra en este poema como una figura sufriente a manos de Dios 
y su «divina baba», que remite al aliento creador y que da vida, que al fin y al cabo es el tiempo que la envejece; sufre porque lleva en su vientre al feto, al Cristo que no es niño ni salvación sino mentira que da origen a toda una religión, un Cristo que vive prisionero dentro de su madre: «Mira mi piel de santa envejecida al paso de tu aliento, mira el tambor estéril de mi vientre que sólo conoce [...] el golpe sordo de tu vientre que hace silbar al prisionero, al feto, a la mentira» (pág. 201). «¿Qué más quieres de mí?», pregunta esta virgen violada, sufriente, dolorosa. ¿Qué más puede pedir un Dios que toma cuerpo y alma, que exige el sacrificio total solo para desatar el Apocalipsis, para destruir la tierra?

En este poema, María se ve convertida, no en madre virgen e incorpórea, sino en madre que sangra, que sufre en cada menstruación por lo que supone de aborto, de pérdida de un hipotético hijo. Se ve convertida incluso en devoradora de hombres, en figura equivalente a Kronos, al tiempo que devora a sus hijos: «Ve lo que has hecho de mí, la madre que devora sus crías, la que se traga sus lágrimas y engorda, la que debe abortar en cada luna, la que sangra todos los días del año» (201). En Varela no existe una maternidad plácida.

No existe tampoco una entrega reverencial como se ve en el Evangelio de Lucas; en el poema no queda rastro de la joven que se presta a parir al Hijo de Dios, pues le ha visto ser cruel, «vertiendo plomo derretido en las orejas inocentes, castrando bueyes» (pág. 201). Tampoco el Dios de Varela es una figura incorpórea, sino una divinidad degradada que se arrastra por su propia creación, y así le ha visto «arrastrando tu azucena, tu inmaculado miembro, en la sangre de los mataderos» (pág. 201). Se le presenta, no como el Dios que crea con la palabra, sino como un pelele, como un cocinero: como un trabajador que también suda con los vapores de su marmita celeste, que no puede permanecer al margen, sino que interviene en los procesos más traumáticos de la historia reciente, como general, como tanquista, como figura violenta.

En los últimos versículos de «Vals del Ángelus», el bestiario que puebla la poesía de Varela vuelve a presentarse en una sucesión demencial, en una acumulación in crescendo en la que aparecen alacranes y serpientes - símbolos de la tentación y el mal, y en el caso del alacrán, atributo de las langostas que atormentan a los hombres en el Apocalipsis: «Tienen colas parecidas a escorpiones, y aguijones; y en sus colas está su poder para hacer daño a los hombres por cinco meses» $(A p 9,10)$-, tortugas desolladas, víboras, potros. 
El uso de un imaginario animal en Varela tiene también una intención desacralizadora, ya que como afirma la propia escritora «más que nada me interesa nuestra animalidad, pero no en sentido peyorativo, sino en el sentido de la mortalidad. Al lado de esto está vivir para trascender, no sé para qué ni para quién» (entrevista con Patrick Rosas, 1999: 76).

Es decir, los rasgos bestiales tanto en el ser humano como atribuidos a Cristo y, por tanto, a Dios, son un método para profundizar en la naturaleza mortal, corporal y en último caso abyecta del ser humano. Este descenso hasta la abyección se puede ver en «Vals del Ángelus», en el que la abundancia de símbolos religiosos culmina en la subversión del polvo del que está formado el hombre - «Con el sudor de tu rostro comerás el pan hasta que vuelvas a la tierra, porque de ella fuiste tomado; pues polvo eres, y al polvo volverás» (Gén 3, 19) - , que en el poema se convierte en estiércol y en cieno, haciendo que el destino de la humanidad ya no sea volver a la tierra de la que fue tomado, sino a la podredumbre de donde viene este «Predestinado estiércol, cieno de ojos vaciados».

A lo largo de sus poemas se encuentran referencias también a Moisés, Abraham, Job y los propios ángeles, todos ellos figuras que se muestran degradadas y que, por el limitado espacio del artículo, no se entrará a analizar en profundidad. Baste mencionarlos para establecer que en el imaginario de Varela no hay un límite en cuanto a qué se puede profanizar e incluso llevar al límite de la abyección escatológica y corporal. Como analiza Cristina Graves, en su poesía «nada, especialmente lo sagrado, aparece como sagrado en el proceso de desencubrimiento de la realidad» (Graves, 1980: 96).

Varela establece continuos diálogos, no solo con la divinidad, sino con autores que afirman sí haber alcanzado la comunicación con Él: la referencia más obvia ya se ha mencionado, los Ejercicios materiales que una vez más "bajan a tierra" y hacen corpóreos los Ejercicios espirituales de San Ignacio de Loyola. De forma menos explícita, en el poema «Ternera acosada por tábanos» Milena Rodríguez advierte la relación entre la vida que pasa ante el espectador en Varela y el Amado, que pasa en la Noche en el poema de San Juan de la Cruz, produciéndose una reescritura también corporal y con un sentido de abyección: «carne en lugar de alma; moscas en lugar de prados; vida que queda, pues, desnuda, sin ningún adorno espiritual, sola ahí, brillando como un desecho, como un despojo, como absoluta y radical nada material» (2008: 221). 
Sin embargo, quizá la relación más evidente y más relevante para el tema de este artículo sea la que la poeta peruana establece con Simone Weil. Esta se ha analizado en profundidad, no solo por el poema que explícitamente le dedica, «Conversación son Simone Weil», sino por la concepción de la experiencia mística que expresó Weil en sus escritos y el reflejo que de ello hace Varela en toda su obra. La pensadora francesa escribió sobre la gracia divina no como un don que desciende sobre los hombres, sino como un movimiento descendente semejante a la gravedad; esto, obviamente, explica en ella no sólo una filosofía sino una praxis de vida, orientada, dentro de las complejas condiciones de la vida moderna, a poner en contacto las experiencias de lo elevado y lo ordinario, lo espiritual y lo material, lo celestial y lo mundanal (Cárcamo-Huechante, 2005: 10). Como se viene analizando en este texto, Varela reproduce este mismo movimiento, lo que Cárcamo-Huechante define como poética del descenso, para resituar las instancias de poder y, en el caso de los símbolos religiosos, para equipararlos y profanizarlos.

«Sus constantes torsiones de las jerarquías de lo elevado y lo bajo, lo superior y lo inferior, lo metafísico y lo material, lo sublime y lo banal, lo ilustrado y lo popular» (Cárcamo-Huechante, 2005: 11) son un rasgo definitorio en la poesía de Varela, que se van acentuando a medida que su obra refleja, por una parte, una visión más personal del mundo y, por otra parte, una reflexión existencial que hace que se acentúe no solo la resignificación de jerarquías, sino también el sentimiento de desencanto y de náusea respecto a lo que observa en la creación (Gazzolo, 2007). Esto se ve reflejado en el poema «Conversación con Simone Weil», en el que la voz poética dialoga con la pensadora: «- los niños se van a la cama hambrientos. / - los viejos se van a la muerte hambrientos. / El verbo no alimenta. Las cifras no sacian» (Valses y otras falsas confesiones, 224). Ya se ha establecido en este artículo la identificación entre Dios y el Verbo, que en este poema no aparece con mayúscula, de la misma manera que la divinidad. En un mundo en el que la muerte por inanición es una situación innegable, ¿cómo puede alguien saciarse de Pan, de Palabra, del cuerpo de Cristo?

6 Cárcamo-Huechante analiza estos versos como parte de la reflexión no únicamente religiosa y existencial de ambas, poeta y pensadora, sino también de su activismo social, que llevó a Weil a morir de inanición tras una prolongada huelga de hambre. Sin embargo, en el contexto de su obra completa y teniendo en cuenta que Weil es una de las pensadoras cristinas más relevantes del siglo XX, establecer una relación con la divinidad en este poema resulta también inevitable. 
Es posible interpretar que, a consecuencia de este desencanto continuado con el Creador, en Canto villano ya no se alabará a un Dios bíblico, sino a la propia vida sacralizada por la poesía: «y te rendimos diosa / el gran homenaje / el mayor asombro / el bostezo» («A la realidad», 234). Aunque el poema se dedica a la realidad, y por ello a un ente femenino, no deja de ser una provocación escribir a la diosa, frente a un Dios que es Padre, que es Hijo, que es hombre. Pero incluso esta diosa elegida está presente en elementos mundanos, vulgares de la vida, como el bostezo: una vez más la torsión de jerarquías tradicionales en Varela pone en el mismo plano el mayor asombro y una expresión de aburrimiento.

Por último, es necesario analizar un motivo constante tanto en la obra de Varela como en la iconografía cristiana: la luz. Según el Génesis, la primera creación de Dios fue la luz: «Entonces Dios dijo: "Hágase la luz". Y la luz se hizo. Dios vio que la luz era buena, y separó la luz de las tinieblas; y llamó Día a la luz y Noche a las tinieblas. Así hubo una tarde y una mañana: este fue el primer día.» (Gén 1, 3-5) Frente a la asociación tradicional de la divinidad con la luz $-\mathrm{y}$, por tanto, de la luz con todos los conceptos positivos de la Creación -, Varela mostrará una marcada preferencia por la oscuridad. Ya en su primer libro, Ese puerto existe, encontramos referencias negativas respecto a la luz divina: «Todo está preparado para el sacrificio [...]. / La luz crudelísima devora su ración» («Mediodía», p. 148). Los sacrificios buscaban atraer el favor de la divinidad; en «Mediodía», la luz devora el sacrificio de forma cruenta.

Las referencias a la luz continúan en otros poemas, como «Canto villano», con los versos: «aniquilar la luz / o hacerla» (Canto villano, 240). Por el contexto dentro del poema, en el que hay más referencias religiosas («un cielo rebosante / en el plato vacío [...] negros indigeribles milagros / y la estrella de oriente/ emparedada [...] mea culpa ojo turbio / mea culpa negro bocado / mea culpa divina náusea») es posible relacionarlo con esta luz creadora, que la poeta quiere aniquilar. Ante un Dios impasible, ante milagros indigeribles y un mundo abandonado por su creador, el poeta solo tiene dos opciones: matar a Dios, es decir, aniquilar la luz, o asumir el lugar vacante y crear: hacer la luz, y hacerla con la palabra, igual que el Creador original fabricó un mundo en siete días simplemente nombrándolo. El trabajo de creación en la obra de Varela se muestra más complejo, por necesitar de un proceso de desacralización y apropiamiento de la palabra, que se ha analizado hasta ahora en este artículo. 
Esta idea de crear una luz propia ya aparecía en su libro Luz de día: «Hacer la luz aunque cueste la noche, aunque sea la muerte el cielo que se abre y el océano nada más que un abismo creado a ciegas. / La propia voz respondiéndose con el fracaso de cada ola» («Antes del día», p. 172). La propia voz se responde, el poeta habla ante el silencio de un Dios ausente y por ello, debe hacer la luz, aunque cueste la noche, aunque se destruya el espacio de verdadera realidad.

Esta apropiación de la luz y el poder creador de Dios constituye un paso natural en su poética del descenso; aunque la existencia de una entidad divina es continua en la obra vareliana, lo cierto es que esta no responde a las preguntas e increpaciones de la voz poética como de los personajes bíblicos que intervienen en el texto. Quizá esto responda a la propia experiencia de la autora, que afirma no haber tenido nunca una buena relación con Dios, pero también puede deberse a su concepción de la poesía:

Yo creo que lo que establece el poeta es un diálogo. Un diálogo consigo mismo. $Y$ a veces el personaje que te responde eres tú mismo. La primera y la segunda persona se pueden alternar sin problema, ¿no? Te diré que yo no me detengo a reparar en quién está hablando. Estoy hablando yo. Yo siempre he dicho una cosa que ahora suena un poco naive: que yo creo que empecé a escribir porque nadie me respondía las grandes preguntas. Los mayores me mentían. Entonces, yo tuve que interrogarme e inventarme un interlocutor que no podía ser Dios. Me di cuenta de que no era Dios. (Entrevista con Patrick Rosas, 5).

En todo caso, se produce en su obra un fenómeno de diálogo unidireccional que resulta en una interpretación desencantada de la realidad y del Padre que debería responder a sus hijos, que debería solucionar sus grandes preguntas, lo que da como resultado una vez más la degradación de la divinidad ${ }^{7}$.

Ilustrador de esta visión cáustica, apocalíptica, es el último verso del «Vals del Ángelus»: «Tu imagen en el espejo de la feria me habla de una terrible semejanza». Si «Dijo Dios: Hagamos al hombre a nuestra imagen, conforme

\footnotetext{
7 «Esta imposibilidad de dar un salto de nivel obedece a la ausencia de un dios (siempre escrito con minúsculas), sea porque no existe o porque no tutela adecuadamente a los seres humanos, guiándolos en esta ceguera. En tal caso, serán deidades degradadas» (Martínez Pérsico, 2010: 6-7), en su artículo sobre la escatología y el escepticismo en la poesía de Varela.
} 
a nuestra semejanza» (Gén 1, 26), ver su imagen en el espejo deformante de una feria, de un circo, del lugar donde habitan los esperpentos y los monstruos del mundo, habla de la terrible semejanza del ser humano: el Dios del que habla Varela en este poema es cruel, está ausente, se arrastra por el cieno y es encarnación de lo abyecto, y de la misma manera obliga a hacerlo a su creación.

A raíz del análisis de la obra de Blanca Varela, hay una conclusión clara: en su poética no existe salvación posible-«Salvación de qué. Para qué. Cuándo. Férreo sinsentido.» (El libro de barro, «Después de la gran ola el aire se detiene», 307) - : tal y como afirma Martínez Pérsico, «la palabra, en Varela, no libera. El poema no salva porque no contesta el enigma primordial» (2010: 5). A las preguntas constantes de la voz poética, el Padre que debería resolver los grandes problemas de la humanidad no lo hace: los niños siguen muriendo de hambre, las mujeres siguen sufriendo; es más, el ser humano se muestra también cruel, indiferente y bestializado en sus poemas, estableciendo así una doble dirección de creación: de la divinidad a la humanidad, pero también en el sentido contrario.

A través de la simplificación y la desconfianza en el lenguaje simbólico, o al menos en su eficacia, y la progresiva degradación de los símbolos divinos, Varela demuestra en sus poemas que al igual que Dios ha creado al hombre, el hombre ha creado a Dios, pero también puede destruirlo. Tras una conversación infructuosa, la voz poética elige responderse a sí misma, pero también tomar el papel creador que la divinidad no puede asumir. De esta manera, Varela reclama para sí el Verbo y la luz divina, construyendo su propio mundo. Haciendo la luz, aunque cueste la noche.

\section{REFERENCIAS BIBLIOGRÁFICAS}

Bajtín, Mijaíl (1993), Problemas de la poética de Dostoievski, México, Fondo de cultura económica S. A.

BARRIENTOS, Violeta (2008), «La náusea vareliana» en Dreyfus y Silva Santisteban (compiladoras), Nadie sabe mis cosas, Lima, Fondo de Cultura Económica, págs. 221-228. 
CÁrcamo-Huechante, Luis (2005), «Una poética del descenso: Mezcla y conversación en Blanca Varela» en Hispanic Review, Vol. 73, No1, 1-23.

DonAT, Mara (2015), «El tópico del hambre como construcción metafórica del sentido en la poesía de Blanca Varela», en Otras Modernidades, No. 13, 51-67.

FERRÉ, Rosario (1982), Fábulas de la garza desangrada, Cambridge, Schoenhofs Foreign Books.

Gazzolo, Ana María (2007), «Blanca Varela: más allá del dolor y del placer» en Dreyfus M., Silva Santisteban R. (eds.), Nadie sabe mis cosas, Lima, Fondo del Congreso del Perú, 73-83.

GIRARD, René (2012), El sacrificio, Madrid, Editorial Encuentro.

Graves, Cristina (1980), «Con el ángel entre los dedos», en Hueso húmero, No. 14, 93-101.

Hermosilla Álvarez, María Ángeles (2014), «La poesía de mujeres en España: la búsqueda de una identidad» en Revista Surco Sur, Vol. 4: Iss. 6, págs. $45-60$.

MARTínez Pérsico, Marisa (2010), «Escepticismos y escatología en la poesía circular de Blanca Varela» en Revista Electrónica de Estudios Filológicos, No. 19.

Muñoz Carrasco, Olga (2007), Sigiloso desvelo: la poesía de Blanca Varela, Lima, Fondo Editorial de la Universidad Católica del Perú.

Rosas, Patrick (1999) «Hay que vivir como si fuera el día definitivo (Entrevista con Blanca Varela)» en Quehacer, No. 118, 75-78.

Rebaza Soraluz, Luis (2010), «Blanca Varela, desde Ese puerto existe hasta Canto Villano: la construcción de una artista peruana contemporánea.» en Separata: revista de pensamiento y ejercicio artístico, 5, págs.61-64.

ReIsz, Susana (1996), Voces sexuadas: género y poesía en Hispanoamérica, Zaragoza, Asociación Española de Estudios Literarios Hispanoamericanos.

Rodríguez, Lydia H y Figuera, María (2008), Mosaico literario: sobre autoras latinoamericanas y caribeñas, Caracas, Universidad Católica Andrés Bello. 
RodríGuez GutiérRez, Milena (2008), «La metáfora animal: en torno al bestiario de Blanca Varela», en Revista de crítica literaria latinoamericana, No. 68, 211-223.

SALAZAR, Ina. (2011), «Jorge Eduardo Eielson y Blanca Varela: reescrituras místicas desde una modernidad desmiraculizada.» en Les Ateliers du Séminaire Amérique Latine n5, págs. 1-17.

SuÁreZ, Modesta (2003), Espacio pictórico y espacio poético en la obra de Blanca Varela, Madrid, Verbum Editorial.

Uzquiano, Gabriel (2010), «Ángeles y demonios» en Investigación y Ciencia: Edición española de Scientific American, 402, págs. 92-93.

Varela, Blanca (2007), Aunque cueste la noche, Salamanca, Ediciones Universidad de Salamanca. 